\title{
Characteristics of Settings and Etiologic Agents of Foodborne Disease Outbreaks - China, 2020
}

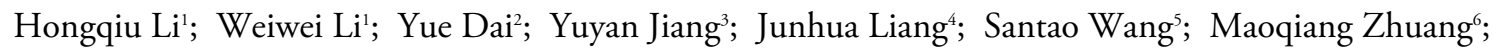

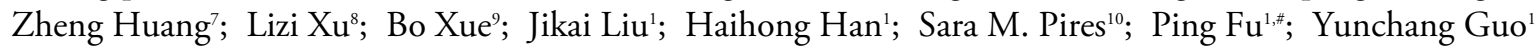

\section{ABSTRACT}

Introduction: Foodborne diseases are a growing public health problem and have caused a large burden of disease in China. This study analyzed epidemiological characteristics of foodborne diseases in China in 2020 to provide a scientific basis for prevention and control measures.

Methods: Data were collected from 30 of 31 provincial-level administrative divisions (PLADs) in the mainland of China, excluding Xizang (Tibet) Autonomous Region, via the National Foodborne Disease Outbreaks Surveillance System. The number and proportion of outbreaks, illnesses, hospitalizations, deaths by setting, pathogen-food category pairs and etiology were calculated.

Results: In 2020, 7,073 foodborne disease outbreaks were reported, resulting in 37,454 illnesses and 143 deaths. Among the identified pathogens, microbial pathogens were the most common confirmed etiology, accounting for $41.7 \%$ of illnesses. Poisonous mushrooms caused the largest proportion of outbreaks $(58.0 \%)$ and deaths $(57.6 \%)$. For venues where foodborne disease outbreaks occur, household had the highest number of outbreaks $(4,140)$ and deaths (128), and catering service locations caused the largest proportion of illnesses (59.9\%). Outbreaks occurring between June and September accounted for $62.8 \%$ of total outbreaks.

Conclusions: Foodborne disease outbreaks mainly occurred in households. Microbial pathogens remained the top cause of outbreak-associated illnesses. Poisonous mushrooms were ranked the top cause of deaths in private homes in China. The supervision and management of food safety and health education should be strengthened to reduce the burden of foodborne diseases. Publicity should be increased to reduce the incidence of mushroom poisonings in families, and supervision and management of food should be strengthened to reduce microbial contamination.

\section{INTRODUCTION}

An outbreak of foodborne disease is defined as the occurrence of two or more cases of a similar illness resulting from ingestion of a common food (1). It is a global health problem that is harmful to humans. Foodborne diseases encompass a wide spectrum of illnesses, including infectious diseases caused by microorganisms and toxic diseases mainly caused by chemical and toxic agents. The World Health Organization estimated that 600 million foodborne diseases occurred globally in 2010, causing 420,000 deaths (2). The US CDC estimated that 48 million foodborne diseases ( 1 in 6 Americans) occur each year in the USA, resulting in 12,800 hospitalizations and 3,000 deaths (3). In the Western Pacific Region, including China, 125 million people get sick and more than 50,000 die every year due to foodborne diseases (4). Foodborne diseases bring huge economic burdens to human beings. According to the requirements of Food Safety Law of the People's Republic of China, the National Foodborne Disease Outbreaks Surveillance System was established to continuously and systematically collect data on foodborne disease outbreaks in 2010.

Therefore, the objectives of this study were to characterize the epidemiological status of foodborne diseases in China and to analyze the distribution of high-risk foods and pathogenic factors to provide technical support for food safety risk assessment, formulation and revision of standards, and risk management.

\section{METHODS}

The study obtained data on foodborne disease cases reported through the National Foodborne Disease Outbreaks Surveillance System from January 1, 2020 to December 31, 2020. Data were collected from 30 of 31 provincial-level administrative divisions (PLADs) in the mainland of China, excluding Xizang (Tibet) Autonomous Region. Data requested for each outbreak 
report included the individual $\mathrm{CDC}$ reporting the outbreak, date of occurrence, number of illnesses, hospitalizations, and deaths, etiology, implicated food(s) and setting. All variable values were reported as counts or proportions (\%). The number and proportion of outbreaks, illnesses, and deaths by etiology, setting, and food categories were calculated. The statistical analysis was performed using SPSS (version 21.0, IBM Corp, Chicago, USA).

\section{RESULTS}

Most outbreaks (97.5\%), illnesses (98.0\%), and deaths $(99.1 \%)$ were linked to households and catering service locations. Households and catering service locations were the most common settings of reported outbreaks. In 2020, the highest number of outbreaks occurred in households $(4,140)$, followed by catering service locations (2,719), and school campuses (27). Most illnesses $(59.9 \%)$ were reported in catering service locations, followed by households $(37.6 \%)$, and $0.5 \%$ in campuses. Within catering service locations, street stalls accounted for the largest proportion $(26.2 \%)$ of outbreaks, and school canteens accounted for the largest proportion (13.6\%) of illnesses. However, households had the most deaths, accounting for $89.5 \%$ of all deaths (Table 1); poisonous mushrooms (79 deaths), aconite (10 deaths), bongkrek acid (11 deaths), and methanol (8 deaths) were the most common causes of deaths, accounting for $84.4 \%$ of total deaths in private home settings.

In 2020, there were 4,662 outbreaks with confirmed etiology. Poisonous mushrooms were the most common cause of outbreaks and deaths, accounting for $58.0 \%$ of outbreaks and $57.6 \%$ of deaths; bacterial pathogens were the most common cause of illnesses $(41.7 \%)$; in poisonous animals and plants and their toxins, undercooked Phaseolus was the most common cause leading to the largest proportion of outbreaks $(31.2 \%)$ and illnesses $(33.3 \%)$; aconite had the most deaths, accounting for $57.1 \%$. Within microbial pathogens, Salmonella (286 outbreaks and 3,446 illnesses) was the most common bacterial pathogen associated with outbreaks and illnesses, followed by Vibrio parahaemolyticus (128 outbreaks and 1,848 illnesses), and Staphylococcus aureus (75 outbreaks and 954 illnesses). Bongkrek acid accounted for the largest proportions $(75.0 \%)$ of deaths and the largest fatality rate $(52.2 \%)$. Among the chemical agents, nitrite was the most common pathogenic factor associated with outbreaks $(49.1 \%)$ and illnesses (49.6\%), followed by pesticide $(32.5 \%$ outbreaks and $27.7 \%$ illnesses); methanol had the highest death and fatality rates at $63.6 \%$ and $25.0 \%$, respectively, followed by nitrite at $22.7 \%$ and $1.1 \%$, respectively (Table 2 ).

In 2020, outbreaks that occurred at households $(7,073)$ had surpassed those of catering service units $(5,652)$, and outbreaks (485) and outbreak-associated illnesses $(6,661)$ caused by Salmonella surpassed those

TABLE 1. Number and proportion of foodborne disease outbreaks, illnesses, and deaths by setting in China, 2020.

\begin{tabular}{|c|c|c|c|c|c|c|c|}
\hline \multirow[b]{2}{*}{ Setting } & \multicolumn{2}{|c|}{ Outbreaks } & \multicolumn{2}{|c|}{ Illnesses } & \multicolumn{2}{|c|}{ Deaths } & \multirow{2}{*}{$\begin{array}{c}\text { Fatality rate* } \\
(\%)\end{array}$} \\
\hline & Number & $\begin{array}{c}\text { Proportion } \\
(\%)\end{array}$ & Number & $\begin{array}{c}\text { Proportion } \\
(\%)\end{array}$ & Number & $\begin{array}{c}\text { Proportion } \\
(\%)\end{array}$ & \\
\hline Household & 4,140 & 58.5 & 14,066 & 37.6 & 128 & 89.5 & 0.9 \\
\hline Catering Service Places & 2,719 & 38.4 & 22,432 & 59.9 & 15 & 10.5 & 0.1 \\
\hline Street stall & 712 & 10.1 & 2,659 & 7.1 & 3 & 2.1 & 0.1 \\
\hline Hotel restaurant & 508 & 7.2 & 4,184 & 11.2 & 5 & 3.5 & 0.1 \\
\hline Staff canteen & 371 & 5.3 & 3,607 & 9.6 & 1 & 0.7 & 0.0 \\
\hline School canteen & 310 & 4.4 & 5,081 & 13.6 & 0 & 0.0 & 0.0 \\
\hline Bistro & 291 & 4.1 & 1,473 & 3.9 & 3 & 2.1 & 0.2 \\
\hline Fast food restaurant & 240 & 3.4 & 1,171 & 3.1 & 0 & 0.0 & 0.0 \\
\hline Rural banquet & 130 & 1.8 & 2,165 & 5.8 & 3 & 2.1 & 0.1 \\
\hline Home delivery of meal & 110 & 1.6 & 1,807 & 4.8 & 0 & 0.0 & 0.0 \\
\hline Other & 47 & 0.7 & 285 & 0.8 & 0 & 0.0 & 0.0 \\
\hline Campus & 27 & 0.4 & 196 & 0.5 & 0 & 0.0 & 0.0 \\
\hline Other location & 187 & 2.6 & 760 & 2.0 & 0 & 0.0 & 0.0 \\
\hline Total & 7,073 & 100.0 & 37,454 & 100.0 & 143 & 100.0 & 0.4 \\
\hline
\end{tabular}

* Fatality rate=number of deaths / number of illnesses. 
TABLE 2. Number and proportion of foodborne disease outbreaks, illnesses, and deaths by etiology in China, 2020.

\begin{tabular}{|c|c|c|c|c|c|c|c|}
\hline \multirow{2}{*}{ Etiology } & \multicolumn{2}{|c|}{ Outbreaks } & \multicolumn{2}{|c|}{ Illnesses } & \multicolumn{2}{|r|}{ Deaths } & \multirow{2}{*}{$\begin{array}{l}\text { Fatality } \\
\text { rate }^{*}(\%)\end{array}$} \\
\hline & Number & Proportion (\%) & Number & Proportion(\%) & Number & Proportion(\%) & \\
\hline Poisonous mushrooms & 2,705 & 38.2 & 9,111 & 24.3 & 80 & 55.9 & 0.9 \\
\hline Plant and animal toxicants & 1,020 & 14.4 & 4,584 & 12.2 & 21 & 14.7 & 0.5 \\
\hline Undercooked Phaseolus* & 318 & 4.5 & 1,526 & 4.1 & 0 & 0.0 & 0.0 \\
\hline Coriaria sinica & 111 & 1.6 & 354 & 1.0 & 0 & 0.0 & 0.0 \\
\hline Potherb & 93 & 1.3 & 355 & 1.0 & 1 & 0.7 & 0.3 \\
\hline Aconite & 84 & 1.2 & 337 & 1.0 & 12 & 8.4 & 3.6 \\
\hline Bitter bottle gourd & 48 & 0.7 & 381 & 1.0 & 0 & 0.0 & 0.0 \\
\hline Tungoil or seed & 46 & 0.7 & 238 & 0.6 & 0 & 0.0 & 0.0 \\
\hline Hyoscyamine & 33 & 0.5 & 183 & 0.5 & 1 & 0.7 & 0.6 \\
\hline Herb-medicine & 27 & 0.4 & 110 & 0.3 & 0 & 0.0 & 0.0 \\
\hline Elephant's-ear & 24 & 0.3 & 86 & 0.2 & 0 & 0.0 & 0.0 \\
\hline Sproutedpotato/solanine & 17 & 0.2 & 97 & 0.3 & 2 & 1.4 & 2.1 \\
\hline Colchicin & 12 & 0.2 & 78 & 0.2 & 0 & 0.0 & 0.0 \\
\hline Gelsemine & 11 & 0.2 & 64 & 0.2 & 3 & 2.1 & 4.7 \\
\hline Castor bean & 10 & 0.1 & 58 & 0.2 & 0 & 0.0 & 0.0 \\
\hline Pokeberry root & 10 & 0.1 & 42 & 0.1 & 1 & 0.7 & 2.4 \\
\hline Sago seed & 10 & 0.1 & 36 & 0.1 & 0 & 0.0 & 0.0 \\
\hline Barbados nut & 9 & 0.1 & 41 & 0.1 & 0 & 0.0 & 0.0 \\
\hline Undercooked soymilk/Trypsin inhibitor $^{\dagger}$ & 3 & 0.0 & 18 & 0.1 & 0 & 0.0 & 0.0 \\
\hline Other plants toxicants $\S$ & 83 & 1.2 & 285 & 0.8 & 0 & 0.0 & 0.0 \\
\hline Fish roe & 19 & 0.3 & 51 & 0.1 & 0 & 0.0 & 0.0 \\
\hline Tetrodotoxin & 15 & 0.2 & 53 & 0.1 & 1 & 0.7 & 1.9 \\
\hline Pupae & 13 & 0.2 & 60 & 0.2 & 0 & 0.0 & 0.0 \\
\hline langoustine & 10 & 0.1 & 25 & 0.1 & 0 & 0.0 & 0.0 \\
\hline Other animal toxicants ${ }^{* *}$ & 14 & 0.2 & 106 & 0.3 & 0 & 0.0 & 0.0 \\
\hline Bacterial & 766 & 10.8 & 10,483 & 28.0 & 16 & 11.2 & 0.2 \\
\hline Salmonella & 286 & 4.0 & 3,446 & 9.2 & 4 & 2.8 & 0.1 \\
\hline Vibrio parahaemolyticus & 128 & 1.8 & 1,848 & 4.9 & 0 & 0.0 & 0.0 \\
\hline Staphylococcus aureus & 75 & 1.1 & 954 & 2.6 & 0 & 0.0 & 0.0 \\
\hline Escherichia coli & 54 & 0.8 & 1,520 & 4.1 & 0 & 0.0 & 0.0 \\
\hline Bacillus cereus & 50 & 0.7 & 620 & 1.7 & 0 & 0.0 & 0.0 \\
\hline Bacillus proteus & 10 & 0.1 & 149 & 0.4 & 0 & 0.0 & 0.0 \\
\hline Clostridium perfringens & 5 & 0.1 & 287 & 0.8 & 0 & 0.0 & 0.0 \\
\hline Bongkrek acid ${ }^{\dagger \dagger}$ & 5 & 0.1 & 23 & 0.1 & 12 & 8.4 & 52.2 \\
\hline Campylobacter jejuni & 3 & 0.0 & 133 & 0.4 & 0 & 0.0 & 0.0 \\
\hline Clostridium botulinum & 3 & 0.0 & 10 & 0.0 & 0 & 0.0 & 0.0 \\
\hline Listeria monocytogenes & 1 & 0.0 & 28 & 0.1 & 0 & 0.0 & 0.0 \\
\hline Others & 108 & 1.5 & 807 & 2.2 & 0 & 0.0 & 0.0 \\
\hline 2 or more pathogens & 12 & 0.2 & 224 & 0.6 & 0 & 0.0 & 0.0 \\
\hline Norovirus & 26 & 0.4 & 434 & 1.2 & 0 & 0.0 & 0.0 \\
\hline Chemical agents & 163 & 2.3 & 922 & 2.5 & 22 & 15.4 & 2.4 \\
\hline Nitrite & 80 & 1.1 & 457 & 1.2 & 5 & 3.5 & 1.1 \\
\hline
\end{tabular}


TABLE 2. (Continued)

\begin{tabular}{|c|c|c|c|c|c|c|c|}
\hline \multirow{2}{*}{ Etiology } & \multicolumn{2}{|c|}{ Outbreaks } & \multicolumn{2}{|c|}{ Illnesses } & \multicolumn{2}{|c|}{ Deaths } & \multirow{2}{*}{$\begin{array}{c}\text { Fatality } \\
\text { rate* }^{*}(\%)\end{array}$} \\
\hline & Number & Proportion (\%) & Number & Proportion(\%) & Number & Proportion(\%) & \\
\hline Pesticide ${ }^{\S \S}$ & 53 & 0.8 & 255 & 0.7 & 2 & 1.4 & 0.8 \\
\hline Prohibited drugs & 10 & 0.1 & 115 & 0.3 & 1 & 0.7 & 0.9 \\
\hline Methanol & 9 & 0.1 & 56 & 0.2 & 14 & 9.8 & 25.0 \\
\hline Other chemical pollutants ${ }^{* * t}$ & 11 & 0.2 & 39 & 0.1 & 0 & 0.0 & 0.0 \\
\hline Fungi & 7 & 0.1 & 27 & 0.1 & 0 & 0.0 & 0.0 \\
\hline Parasitic & 1 & 0.0 & 4 & 0.0 & 0 & 0.0 & 0.0 \\
\hline Unknown etiology & 2,411 & 34.1 & 12,323 & 32.9 & 4 & 2.8 & 0.0 \\
\hline Total & 7,073 & 100.0 & 37,454 & 100.0 & 143 & 100.0 & 0.4 \\
\hline
\end{tabular}

${ }^{*}$ Refers to uncooked Phaseolus beans.

${ }^{\dagger}$ Contained in uncooked soy milk.

$\S$ Including wild flowers, hellebore, wild ginseng, pollen, daffodils, and wild fruits, etc. Including bee pupae and silkworm pupae.

${ }^{* *}$ Including dog liver, insects, fish gall, toads and ants, etc.

${ }^{\dagger \dagger}$ Including Shigella, Aeromonas, Enterobacter cloacae, Citrobacter flaudus, Schneider, and Enterococcus, etc.

$\S \S$ Including Carbamates, organophosphates, pyrethroids, paraquat, bromfamethamine and bromadiolone, etc. Including clenbuterol hydrochloride, xylazine, and tetramine.

${ }^{* * *}$ Including lead, engine oil, desiccant, chlorine dioxide, and detergent, etc.

of Vibrio parahaemolyticus. Foodborne disease illnesses occurred in school canteens $(5,081)$.

The top 10 pathogen-food category pairs resulting in outbreaks, outbreak-associated illnesses, and deaths were analyzed. Salmonella in eggs had the highest occurrence, accounting for $32.8 \%$ (75/229) of outbreaks, followed by Salmonella in sauce-marinated meat (Table 3). Salmonella in sauce-marinated meat had the highest proportion (21.7\%) of illnesses and $23.2 \%$ of hospitalizations, followed by Salmonella in eggs.

\section{CONCLUSION AND COMMENT}

Influenced by the coronavirus disease 2019
(COVID-19) pandemic, epidemiological characteristics of foodborne diseases in China had changed greatly in 2020 .

For the first time in the past 5 years, outbreaks that occurred in private homes had surpassed that of catering service units in 2020 (5). The local residents in mountainous areas of southwest and central China tended to pick mushrooms and poisonous plants frequently in the wild (G). Continued and targeted health education programs should caution against picking wild mushrooms and toxic wild fruits. Eating habits with regional characteristics should be further emphasized and intervention measures should be taken to reduce the occurrence of poisonings.

The study showed that poisonous mushrooms caused the most deaths, the same as previous studies

TABLE 3. Top 10 number and proportion of most common confirmed pathogen-food category pairs resulting in outbreak in China, 2020.

\begin{tabular}{|c|c|c|c|}
\hline Etiology & Food category & No. outbreaks & Proportion (\%) \\
\hline Salmonella & Egg & 75 & 32.8 \\
\hline Salmonella & Sauce-marinated meat & 44 & 19.2 \\
\hline Salmonella & Pastry & 28 & 12.2 \\
\hline Bacillus cereus & Rice flour & 22 & 9.6 \\
\hline Vibrio prahaemolyticus & Sauce-marinated meat & 17 & 7.4 \\
\hline Salmonella & Livestock meat & 13 & 5.7 \\
\hline Vibrio parahaemolyticus & Crustaceans & 11 & 4.8 \\
\hline Escherichia coli & Sauce-marinated meat & 10 & 4.4 \\
\hline Staphylococcalaureus enterotoxins & Pastry & 9 & 3.9 \\
\hline Salmonella & Poultry & 6 & 100.0 \\
\hline Total & & 229 & 32.8 \\
\hline
\end{tabular}


(5). They were mainly caused by wild mushrooms collected by households $(97.5 \%)$. This was consistent with the research results of Ren et al. (6). Residents picking and eating mushrooms could not distinguish between poisonous mushrooms from non-toxic mushrooms, and the rate of timely treatment after poisoning was low and increased the risk of death. Health education targeted for specific groups in rural areas is also essential to reduce mushroom poisonings.

Outbreaks and illnesses caused by Salmonella surpassed that of Vibrio parahaemolyticus, becoming the first pathogenic bacteria of bacterial foodborne diseases. This analysis on pathogen and food pairs in China showed that Salmonella outbreaks were most often linked to eggs, sauce-marinated meat products. Data showed that Salmonella was responsible for the largest number of outbreaks, hospitalizations, and deaths among meats and eggs; this was consistent with the result from the EU: Salmonella accounted for $36.8 \%$ of deaths in "eggs and egg products" ( 7 ). For Salmonella outbreaks, most outbreak-associated cases in the US were associated with seeded vegetables, eggs, poultry, beef, and pork, which differed from China (8). Pathogenic microbial contamination was still the main pathogenic factor of foodborne diseases in China and an important food safety issue that should not be ignored. Hygiene guidance and education should be done to reduce the burden of foodborne diseases caused by microbial factors.

Therefore, continued surveillance for foodborne disease outbreaks is important to understand changes in the foods, settings, and pathogens associated with illness (9). In order to reduce public health risks, more measures were adopted to enhance awareness of reporting, improve trace-back technology to achieve early detection, early warning, and early control of food safety risks.

This study was subject to at least two limitations. First of all, for many reported outbreaks, information on certain aspects of the outbreaks was missing or incomplete, so the conclusions might not be representative of unknown aetiologies or food categories. Second, reported foodborne disease outbreaks can't represent all actual occurred outbreaks, since underreporting existed for various reasons, such as administrative intervention, insufficient ability of outbreak investigation, etc.

Not all the National Foodborne Disease Outbreaks Surveillance System recorded with the epidemiological information in 2020. Like most countries, there are also cases of under-report, and incomplete information.

Acknowledgements: Members in all participating
CDCs.

Conflicts of interest: No reported conflicts.

Funding: Supported by The National Key Research and Development Program of China (Grant number 2017YFC1601502).

doi: $10.46234 / \mathrm{ccdcw} 2021.219$

\# Corresponding author: Ping Fu, fuping@cfsa.net.cn.

\begin{abstract}
${ }^{1}$ National Health Commission Key Laboratory of Food Safety Risk Assessment, China National Center for Food Safety Risk Assessment, Beijing, China; ${ }^{2}$ Jiangsu Provincial Center for Disease Control and Prevention, Nanjing, Jiangsu, China; ${ }^{3}$ Guangxi Center for Disease Prevention and Control, Nanning, Guangxi Zhuang Autonomous Region, China; ${ }^{4}$ Guangdong Provincial Center for Disease Control and Prevention, Guangzhou, Guangdong, China; ${ }^{5}$ Shanxi Provincial Center for Disease Control and Prevention, Taiyuan, Shanxi, China; 6 Shandong Center for Disease Control and Prevention, Jinan, Shandong, China; ${ }^{7}$ Fujian Provincial Center for Disease Control and Prevention, Fuzhou, Fujian, China; ${ }^{8}$ Anhui Provincial Center for Disease Control and Prevention, Hefei, Anhui, China; ${ }^{9}$ Shaanxi Provincial Centre for Disease Control and Prevention, Xi'an, Shaanxi, China; ${ }^{10}$ National Food Institute, Technical University of Denmark, Lyngby, Denmark.
\end{abstract}

Submitted: May 18, 2021; Accepted: October 12, 2021

\section{REFERENCES}

1. Gould LH, Walsh KA, Vieira AR, Herman K, Williams IT, Hall AJ, et al. Surveillance for foodborne disease outbreaks-United States, 1998-2008. MMWR Surveill Summ 2013;62(2):1-34. https:// pubmed.ncbi.nlm.nih.gov/23804024/.

2. World Health Organization. WHO estimates of the global burden of foodborne diseases. 2015. https://www.who.int/activities/estimating-theburden-of-foodborne-diseases. [2020-3-13].

3. Havelaar AH, Kirk MD, Torgerson PR, Gibb HJ, Hald T, Lake RJ, et al. World Health Organization global estimates and regional comparisons of the burden of foodborne disease in 2010. PLoS Med 2015;12(12):e1001923. http://dx.doi.org/10.1371/journal.pmed.1001 923.

4. Scallan E, Griffin PM, Angulo FJ, Tauxe RV, Hoekstra RM. Foodborne illness acquired in the United States-unspecified agents. Emerg Infect Dis 2011;17(1):16 - 22. http://dx.doi.org/10.3201/eid1701.091101p2.

5. Fu P, Wang LS, Chen J, Bai GD, Xu LZ, Wang S, et al. Analysis of foodborne disease outbreaks in China mainland in 2015. Chin J Food Hygiene 2019;31(1):64 - 70. http://dx.doi.org/10.13590/j.cjfh.2019. 01.014. (In Chinese).

6. Ren JH, Wang XY, Wu XM, Wang R. Epidemiological characteristics of food poisoning in China, July-September, 2018. Dis Surveill 2019;34(8):741 - 5. http://dx.doi.org/10.3784/j.issn.1003-9961.2019. 08.014. (In Chinese).

7. European Food Safety Authority and European Centre for Disease Prevention and Control (EFSA and ECDC). The European Union summary report on trends and sources of zoonoses, zoonotic agents and food-borne outbreaks in 2017. EFSA J 2018;16(12):e05500. http://dx.doi.org/10.2903/j.efsa.2018.5500.

8. Li WW, Pires SM, Liu ZT, Ma XC, Liang JJ, Jiang YY, et al. Surveillance of foodborne disease outbreaks in China, 2003-2017. Food Control 2020;118:107359. http://dx.doi.org/10.1016/j.foodcont.2020. 107359 .

9. Centers for Disease Control and Prevention (CDC). Surveillance for foodborne disease outbreaks-United States, 2009-2010. MMWR Morb Mortal Wkly Rep 2013;62(3):41-7. https://pubmed.ncbi.nlm.nih.gov/ $23344696 /$ 